\title{
BUILDING INTERACTIVITY IN HIGHER EDUCATION TO SUPPORT STUDENT ENGAGEMENT IN SPATIAL PROBLEM SOLVING AND PROGRAMMING
}

\author{
Elizabeth-Kate Gulland, Bert Veenendaal and Antonius G T Schut \\ Department of Spatial Sciences, Curtin University, Kent St Bentley 6102, Western Australia \\ (e.gulland, b.veenendaal, t.schut)@curtin.edu.au
}

\begin{abstract}
Commission VI
KEY WORDS: student engagement, e-learning, distance learning, spatial problem solving, surveying, geographic information science, spatial sciences education, online teaching and learning
\end{abstract}

\begin{abstract}
:
Problem-solving knowledge and skills are an important attribute of spatial sciences graduates. The challenge of higher education is to build a teaching and learning environment that enables students to acquire these skills in relevant and authentic applications. This study investigates the effectiveness of traditional face-to-face teaching and online learning technologies in supporting the student learning of problem-solving and computer programming skills, techniques and solutions. The student cohort considered for this study involves students in the surveying as well as geographic information science (GISc) disciplines. Also, students studying across a range of learning modes including on-campus, distance and blended, are considered in this study. Student feedback and past studies reveal a lack of student interest and engagement in problem solving and computer programming. Many students do not see such skills as directly relevant and applicable to their perceptions of what future spatial careers hold. A range of teaching and learning methods for both face-to-face teaching and distance learning were introduced to address some of the perceived weaknesses of the learning environment. These included initiating greater student interaction in lectures, modifying assessments to provide greater feedback and student accountability, and the provision of more interactive and engaging online learning resources. The paper presents and evaluates the teaching methods used to support the student learning environment. Responses of students in relation to their learning experiences were collected via two anonymous, online surveys and these results were analysed with respect to student pass and retention rates. The study found a clear distinction between expectations and engagement of surveying students in comparison to GISc students. A further outcome revealed that students who were already engaged in their learning benefited the most from the interactive learning resources and opportunities provided.
\end{abstract}

\section{INTRODUCTION}

Problem-solving skills are an essential graduate attribute for students in the spatial sciences, but are notoriously difficult to teach. Computer programming is a necessary skill for spatial scientists and can be a useful tool for encouraging and developing problem solving (Kordaki, 2010).Problem-solving skills are analogous to critical thinking skills as they combine the need for understanding the problem, assembling a sequence of steps to solve it and testing the solution's efficacy. The problem of managing the combination of domain knowledge and critical thinking in education has been investigated in several areas such as business, education, politics, law, medicine and nursing (Kek and Huijser, 2011) although research into student motivation in technological areas such as computing has been scarce (Hawi, 2010).

The unit of study investigated in this research is called Spatial Computations $(\mathrm{SpC})$ which focusses on problem solving and computer programming knowledge and skills. This unit is compulsory in the geographic information science (GISc) and surveying programs run by the Department of Spatial Sciences at Curtin University.

Student engagement with the content of the $\mathrm{SpC}$ unit has historically been quite low, particularly with undergraduate surveying students who struggle to see its relevance to their course. This is compounded by the problems inherent in learning programming skills as a novice, including the combination of understanding a problem, solving it, choosing the code structures to use and then testing the solution (Falkner, 2009).
A number of modifications have been applied to this unit over the period 2009-2011 in an effort to improve student engagement and retention in the unit (Gulland et al., 2011).

The general aim of this work is to develop more effective teaching and learning methods and means of skills and content delivery to enhance problem solving skills and basic computer programming knowledge. Previous work focussed on the differences between student cohorts, in particular between fully online and on-campus students (Gulland et al., 2011).

\subsection{Objectives}

The objective of the research outlined in this paper is to quantify the effects of interactive learning activities on student engagement and student attitudes towards the subject material.

\section{BACKGROUND}

Spatial Computations $(\mathrm{SpC})$ is a requirement for graduation in all study programs within the Department of Spatial Sciences, including Bachelor of Science courses in Geographic Information Science (GISc) and Mine \& Engineering Surveying, Bachelor of Surveying, and postgraduate courses in GISc, Surveying and Mapping, and Geospatial Science (Gulland et al., 2011).

The unit is offered in both traditional on-campus and fullyonline distance mode. As shown in Table 1, most undergraduate 
students study in on-campus mode but more than half of postgraduate spatial students study in fully-online mode.

\begin{tabular}{|c|c|c|}
\hline Course of study & $\begin{array}{c}\text { Number of } \\
\text { students }\end{array}$ & $\begin{array}{c}\% \text { studying } \\
\text { online }\end{array}$ \\
\hline Surveying or Mine Surveying & 56 & $5 \%$ \\
undergraduate & 13 & $5 \%$ \\
GISc undergraduate & 34 & $64 \%$ \\
GISc postgraduate & 12 & $49 \%$ \\
Other postgraduate & \\
\hline
\end{tabular}

Table 1. Average student numbers in the $\mathrm{SpC}$ unit by course of study, 2009-2011

It has been observed since the introduction of $\mathrm{SpC}$ into the Bachelor of Surveying course that surveying students tend to resist learning computer programming as they are more focussed on fieldwork (Gulland et al., 2011).

It is well known that student engagement has a positive effect on student retention (Boddy, 2010) and this also holds true for this unit.

Postgraduate students in $\mathrm{SpC}$ tend to have a much higher pass and retention rate than undergraduate students (Gulland et al., 2011). Undergraduate students engage less in the $\mathrm{SpC}$ unit and their retention rates are lagging. Student engagement with the material is affected by their attitudes towards it. It is assumed that the postgraduate students are more motivated and have a more positive approach to learning programming skills than undergraduate students.

Because of these trends in the unit, undergraduate students have been the primary target for new interactive resources and teaching methods.

\section{DELIVERY OF CONTENT}

Pedagogies focussing on student engagement include problembased learning, cooperative or collaborative learning, and simulations. To implement any of these in full requires a large resource input, without guaranteed success (Hallinger and $\mathrm{Lu}$, 2011). Yet, the past decade has seen substantial developments in the provision of engaging, interactive and online learning resources utilised in flexible spatial learning environments (Carver, 2005; Veenendaal, 2000; Veenendaal, et al., 2005).

Some aspects of these teaching styles were trialled in the $\mathrm{SpC}$ unit over the period 2009-2011. They included online forums and in-lecture tools to encourage collaboration between student groups, simulations of programming concepts (both as online animated tools and as a face-to-face interactive game within a lecture) and assignment and practical exercises designed to introduce some traits of problem-based learning.

\subsection{Web Based Lecture Technologies (WBLT)}

In the years 2009-2011, a number of online resources were made available to all students. In addition to lecture notes and practical instruction sheets, these included automatically recorded audio and video of each lecture, discussion forums involving peers and instructors, online assignment submission, quiz formative assessments and a range of interactive online tools that assist the student with particular concepts and skills.
Coordinators of the $\mathrm{SpC}$ unit have been using web-based iLecture technologies to record lectures (Preston et al., 2010), and deliver them to students digitally since the mid 2000's. Both on-campus and distance students can access and engage with online iLecture recordings as well as learning activity sheets and other resources.

The availability of online lecture recordings has been shown to have minimal effect on lecture attendance (von Konsky et al., 2009), although this can vary between different student cohorts.

In 2011, short online videos introducing practical sessions were added to the online resources. These were a combination of a 'talking head' message from the unit coordinator and/or screenshots demonstrating some of the tasks to be followed in the practical. Students could use these to receive or review instructions regarding the context and tasks to be carried out, as well as to see hints for performing their practical work.

\subsection{Practical Work}

From 2010 onwards, students' developing skills were assessed with open-book online quizzes which included questions taken directly from the practical sessions. These quizzes were designed as formative assessment to replace the older system of submitting practical exercises on paper for marking by tutors.

The instructor gave students direct feedback about quiz answers in lectures. Online quizzes were selected as the appropriate tool for formative assessment because it was found (Veenendaal, 2001) that they were well accepted by students, and that they provided constructive feedback, flexibility and motivation for students.

Also in 2010, the summative practical assignment was enhanced so that progress in weekly practical exercises could be incorporated immediately by students into the assignment. Methods and algorithms developed in practical sessions could be re-used or slightly modified to be used in the marked assignment. The assignment was submitted in two parts so that constructive formative feedback for the first part could be used in the second.

As well as highlighting the relevance of early, building-block tasks to general programming skills, this design change aimed to encourage students to reflect on and commence the assignment earlier. It also introduces some concepts commonly used as part of problem based learning (PBL).

PBL focusses on student-based learning. In essence, a new concept starts as a problem rather than a didactically described theory. The problem needs to be a realistic one similar to one that may be faced in industry, and students take more responsibility for their own learning (Hallinger and Lu, 2011). The PBL trait of small group learning was not formally followed, although many students in on-campus tutorial classes tended to naturally work in small groups, aided by the laboratory layout with four computers grouped around each desk. Also, students did not have to demonstrate complete solutions (as in most PBL-based experiences) except in a limited way during the one-on-one practical checks (see Section 3.4).

\subsection{On-Campus Lectures}

Improving student engagement within on-campus lectures was an important target, as the student cohort that has been most at 
risk of low retention and engagement historically has been oncampus undergraduate students, particularly in surveying courses (see Section 2). Improving the appeal and perceived relevance of lectures has an added advantage as they can also be accessed online via iLecture recordings by other student groups, including distance students, though not all activities are suited to this format.

\subsection{Interactive components of delivery}

Discussion Forum: All students are encouraged to interact online using the discussion forum on the unit's learning management site. Distance students are particularly urged to use the online forum in order to develop the online community (Kehrwald, 2008) that would otherwise be lacking due to their inability to attend on-campus activities. Both distance and oncampus students interact in this common online forum regarding lecture content, practical session difficulties, administrative issues involving assessments and due dates and other unit-related aspects and issues.

Programming Clinics: interactive face-to-face clinics were first introduced in 2009. The clinics were designed as open sessions where students could bring problems and questions about programming for extra help outside scheduled practical sessions.

For the first time in 2011, programming clinics were made compulsory for on-campus students who received $45 \%$ or lower in a quiz. This was intended to get early help to students who were struggling with the concepts.

Practical Checks: These were introduced in 2011 so that students could learn and assimilate essential skills and concepts by demonstrating them to a tutor. At the same time, tutors could use them to gauge the students' level of progress and give immediate feedback and assistance to individual students.

Three practical checks were designed, though only the first two were implemented in 2011. In each, the student had to demonstrate and explain a small task to their tutor. On-campus students had to complete each task in order to pass the unit to ensure compliance.

Each task that students demonstrated highlighted an essential programming skill (Gulland et al., 2011):

- Debugging and documenting code (week 3)

- Calling procedures in code (week 6)

- Writing procedures in code (week 8)

The first check was seen as particularly important. As well as demonstrating familiarity with the programming environment and tools for testing code, it was a way to emphasise the logic flow of a solution. This is related to general problem solving ideas such as breaking a problem into manageable pieces and designing solutions. It was also important to embed this skill early on, so that students could follow the flow of their own code and use tools to find and fix errors.

The checks were best suited to on-campus students. Distance students were instead asked to provide their distance tutor with screen captures and written explanation for the same task. This was not ideal as it lacked the direct interaction that on-campus students gained. Further development is needed in this area.

Interactive Response Units (clickers): In 2011, handheld clickers were introduced to on-campus lectures. These were used by students during the lectures to respond to questions in real time. Clicker responses are completely anonymous, which helps to encourage greater participation, honesty and interaction from students (Kay and LeSage, 2009).

Variable Game: Variables are a fundamental concept in programming and a lack of understanding at this stage causes problems with more advanced ideas later in the unit. To demonstrate the concept, a game was introduced in the third lecture to involve students more directly in the concept of how variables worked. Students were assigned roles within a program and then sealed instructions were given to the first student to start an interaction between students acting as variables and those acting as processes.

Question \& Answer Session: One complete lecture (week 7) was almost entirely given over to an interactive, face-to-face question and answer seminar. Students asked questions about the topics they wanted more help with, and the lecturer demonstrated problems and solutions on the fly. This lecture was roughly midway through the unit, and immediately followed the topic of multi-dimensional arrays and file reading, where many students start having significant difficulties. This was a live, face-to-face session primarily aimed at on-campus students. Distance students were encouraged to send in topics and problems encountered to be discussed in the session by email. The discussion was made available afterwards via iLectures.

\section{METHODOLOGY}

In each year 2009-2011, student data was collected at the end of the semester for pass and retention rates, courses studied and mode of study (distance or on-line). Also, student responses to the university-wide eVALUate student feedback survey were collated.

In addition, student responses were collected during the 2011 semester from in-lecture responses using clickers and from two online surveys.

\subsection{Questions for Clickers}

The clickers were used by students to respond anonymously to a multiple-choice question projected as a lecture slide. Each student could choose only one response. Grouped results were then displayed (and saved as part of iLecture recordings). Ten of the twelve lectures in 2011 included between three and five clicker questions.

Questions posed to students served multiple purposes. They included review questions to help the teacher and students understand what areas needed more work, forward-looking questions to encourage students to think about problems in the subject area, skill testing questions, and demographic and attitude questions for research and comparison.

Some questions were asked in order to focus the students attention onto a study resource available to them or a specific problem area.

\subsection{Surveys}

General student feedback is collected on all Curtin University units using the eVALUate survey tool. Students can respond to this survey to give feedback on issues such as workload, 
assessments, and their own motivation. This survey is collected at or immediately after the end of the semester teaching period.

For this project in 2011, two additional internal surveys were conducted for SpC students, in weeks 5 and 13 of the semester. Most questions were repeated in both surveys, in order to gauge changes across the semester.

Questions in the two internal surveys were more specific to the unit and to problem solving and computer programming, including students' self-assessment of skill level, use of resources and areas of difficulty.

All three surveys were completely anonymous. The two internal surveys included demographic questions that facilitated separation of answers by course of study and/or study mode (on-campus or fully-online).

\section{RESULTS}

It should be noted that a small number of students studying in fully-online mode were in the local area and could attend some or all on-campus lectures and/or practical sessions. This means that some on-campus results - such as in-lecture clicker answers - may include data from distance students.

\subsection{Web Based Lecture Technologies (WBLT)}

The interest level of undergraduate spatial students in iLecture recordings dropped in the period between the two surveys (Figure 1). There are a number of potential reasons for this - as the last four lectures were less directly applicable to content in the major assignment, they may not have been followed as assiduously; students' focus may have shifted towards working on assessments in computer laboratory in this and other units. The reduced interest in iLecture recordings mirrors the decrease in lecture attendance. There was no evidence for a shift from iLecture viewing to attending on-campus lectures.

For all distance students, iLecture recordings are extremely important. The perceived usefulness of iLectures for undergraduate students did not change strongly during the semester, in contrast to postgraduate students. For the latter cohort, both the agreement for the categories "Not at all useful" and "Extremely important" increased. This may be a sign of heightened or loss of motivation in this student cohort.

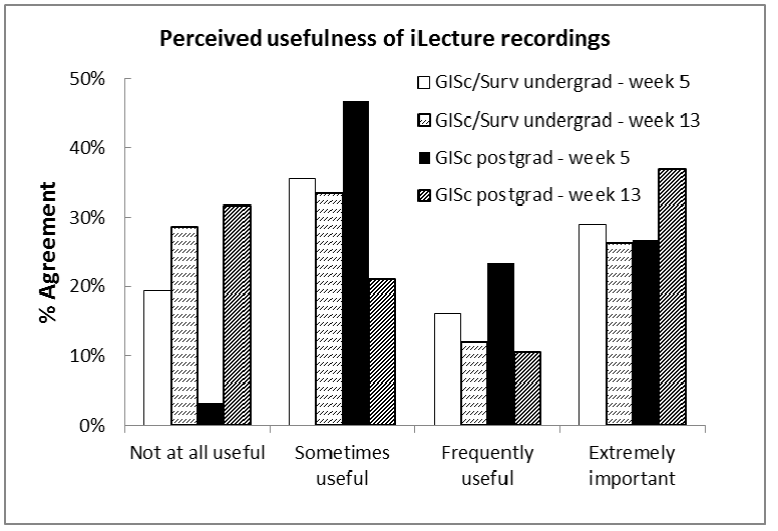

Figure 1: Students' perceptions of the usefulness of iLecture recordings
The students' perception of the usefulness of the introductory practical videos dropped between the two internal surveys in 2011. Responses from the second survey of 2011 showed that $69 \%$ of distance students watched the online practical session introductions always or almost always, compared to only 5\% of on-campus students. This can be expected since the latter cohort attends the on-campus sessions whereas the distance student cohort relies solely on the online communications and resources. The responses in the second survey revealed that $78 \%$ of distance students found the videos useful at least some of the time compared to $48 \%$ of on-campus.

In contrast to the introductory videos, student use of the discussion forum increased over the semester as shown by Figure 2. One factor in this may be the increased awareness of its usefulness for assignment queries after the first assignment deadline in week 5 . It was used most heavily by distance students with $100 \%$ of distance students reporting in the second survey that they used it at least once or twice every week or two, compared to $24 \%$ of on-campus students.

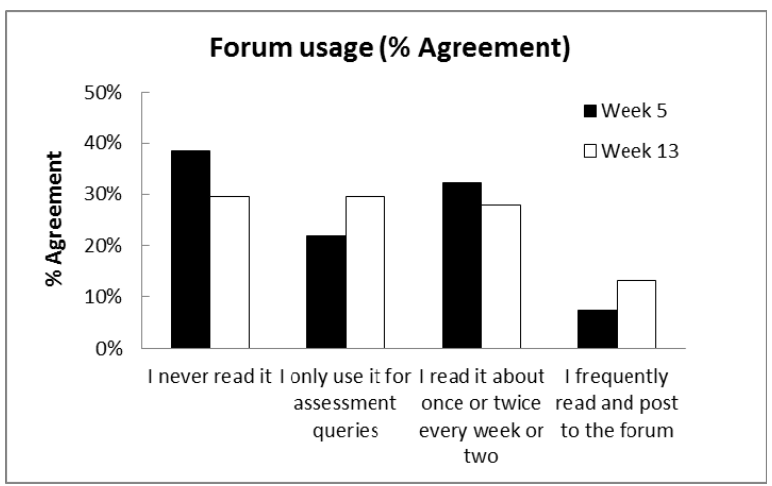

Figure 2: Forum usage (survey responses by students)

As with clicker questions (see Section 4.1), some internal survey questions were designed to direct students' attention to available resources and requirements. For example, the question "How often do you view the online introduction to practical videos?" was asked in both surveys (weeks 5 and 13). In the first survey, $14 \%$ of students responded with "I wasn't aware they were there". In the second survey, this had dropped to $8 \%$. This change may be attributable to the survey itself and/or exposure to the unit material over the period.

\subsection{Practical Work}

In the second survey of 2011, students were asked "How helpful did you find the extra programming clinics put on by the unit?".

Of the students who attended at least one clinic, $57 \%$ of GISc undergraduates (out of $n=11$ ), $78 \%$ of surveying undergraduates $(n=31)$ and $33 \%$ of GISc postgraduates $(n=19)$ found them helpful. In addition, the popularity of the one-on-one clinics is attested to by $31 \%$ of all spatial students who reported that they wanted to attend one or more clinics but could not because of other commitments.

In the second survey, all students were asked how working through the first assignment affected their problem solving skills and also how it affected their programming/coding skills. Most spatial students found that working through the first part of the summative assignment had a positive effect on their skills, with $100 \%$ of undergraduate students selecting 
sometimes, frequently or extremely useful. Only 1 postgraduate student found that the assignment was not useful for either skillset.

The practical checks were successful in encouraging on-campus students to work through practical material - in the second internal survey, $56 \%$ of on-campus students stated that the checks positively influenced the amount of work they put into the practical exercises. $42 \%$ of the same group of students did not think the checks were useful. It is possible that the students did not draw links between their extra work and an improvement in the related skills (Gulland et al., 2011).

\subsection{On-Campus Lectures}

Clickers: Although students' perceptions of the usefulness of clickers was not directly surveyed, qualitative comments from students expressed appreciation for the engagement with material that they triggered.

Variable Game: The first survey was released in the week immediately after the variable game was run. One of the questions was "Did you find the 'variable game' (lecture 3) useful?". $73 \%$ of students found it at least partly useful. Postgraduate students rated it lower, with $43 \%$ saying it was not at all useful. This could be partially attributable to the high proportion of distance students amongst the postgraduates.

Question \& Answer Session: Interaction in the Q\&A session in week 7 was intensive, but attendance was relatively poor. This drop in attendance may help explain some student comments in the eVALUate survey which indicated that there was not enough interaction or extra help for problem areas in lectures.

\subsection{Student Attitudes}

Clicker responses from on-campus students in the first lecture attended largely by students studying in internal mode indicated that a high proportion (nearly $40 \%$ ) were uninterested in learning topics from the unit.

A question in the eVALUate survey (see Section 4.2) asks students how much they agree with the statement "I am motivated to achieve the learning outcomes in this unit". On average over the period $2009-2011,71 \%$ of postgraduate students agreed with this statement.

Of the undergraduates, $70 \%$ of GISc students were motivated whereas only $37 \%$ of surveying (including both Surveying and Mine and Engineering Surveying) students were motivated. This clearly supports previous evidence that it is the surveying undergraduate cohort in particular that lacks the motivation to engage in their learning in this unit.

\subsection{Student Workload and Study Time}

Students, particularly undergraduates, have consistently reported finding the workload in the unit too high. Figure 3 shows the students' agreement with the eVALUate statement "The workload in this unit is appropriate to the achievement of the learning outcomes". The results show that more than half of the students indicated that their workload was high. There is no significant difference between undergraduates and postgraduate students.

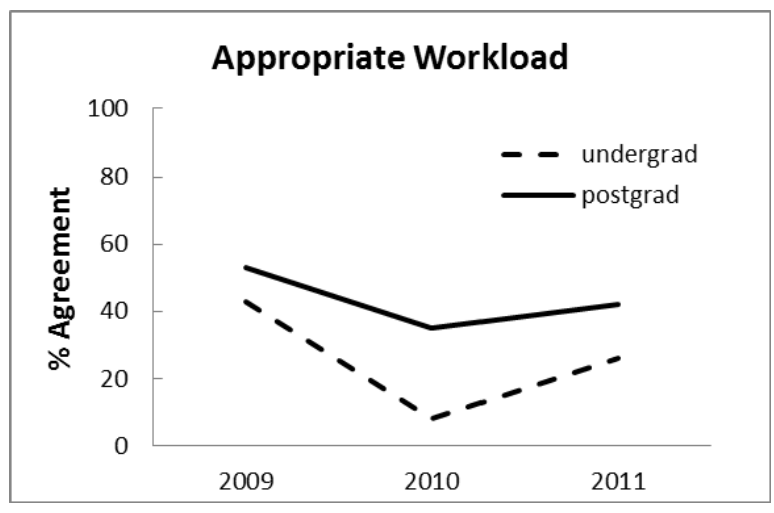

Figure 3. Students' \% agreement with the workload being appropriate to achievement of the learning outcomes

Students were informed that a 25 point credit unit equates to a study load of 10 hours per week on average, so they would need to spend up to six hours per week on average in self-study and carrying out assessments, in addition to the four scheduled contact hours per week. The actual weekly time the majority of students contribute is much lower than ten hours.

On average over the week 5 and 13 responses, $41 \%$ of GISc undergraduates and $49 \%$ of surveying undergraduates indicated that they spent an average total of 5 hours per week or fewer on the unit. Only $17 \%$ of GISc postgraduates indicated similar times. About $10 \%$ of all students indicated that they spent an extra $50 \%$ or more time on the unit than was expected from them.

\section{CONCLUSIONS}

Interactive teaching techniques were developed in the $\mathrm{SpC}$ unit with the aim of improving student engagement in their learning of problem solving and programming skills. Preliminary analysis of the effects of changes implemented in 2010 and 2011 did reveal differences among different student cohorts, although they did not show a significant impact overall on student motivation and engagement.

Practical introductory videos were seen as useful by a majority of distance students but did not appear to improve engagement for on-campus students. In contrast, the variable game was seen as useful by a majority of on-campus students but had a less positive response from distance students

The attitude of students towards the material taught in the unit was vastly different between undergraduate and postgraduate students (see Section 5.4) with more than half of undergraduates still feeling unmotivated at the end of semester, compared to $30 \%$ of postgraduates.

Undergraduate students also appeared to spend less time on the unit. It is unclear if this could be a contributing factor to, or an effect of, their lower motivation.

The motivation rate did not change significantly after new features were added in 2011. Further consideration needs to be applied to improving this, particularly amongst the surveying cohort of students. 
It is evident from the results of this research that the varying student cohorts including undergraduate, postgraduate, GISc and surveying have different expectations, motivations and engagements in their learning. Simply assuming that the same solutions in teaching and learning resources work equally for all students does not produce the desired positive results. In fact, it appears that the existing and newly introduced interactive resources benefitted students who were already engaged, but did not improve motivation for students who were unenthusiastic or to some extent resistant to learning in this unit.

Further research will need to be conducted to ascertain more clearly what the different learning and teaching needs are for different cohorts of students. Simply developing flexible faceto-face and online learning resources as done in the past is not sufficient to address the varying needs among the student population. This will continue to be a challenge for spatial sciences higher education.

\section{REFERENCES}

Boddy, C.R., 2010. A projective technique to help understand the non-rational aspects of withdrawal and undergraduate attrition. Ergo, 1(3): 11-20.

Falkner, K., 2009. Engaging large first year classes. In: C. Kestell, S. Grainger and J. Cheung (Editors), 20th Annual Conference for the Australasian Association for Engineering Education: Engineering the Curriculum, Adelaide, South Australia, pp. 274-279.

Gulland, E.-K., Schut, A.G.T. and Veenendaal, B., 2011. Combining distance and face-to-face teaching and learning in Spatial Computations. In: P. Shih (Editor), ISPRS. ISPRS, Taipei, Taiwan.

Hallinger, P. and Lu, J., 2011. Implementing problem-based learning in higher education in Asia : challenges, strategies and effect. Journal of Higher Education Policy and Management, 33(3): 267-285.

Hawi, N., 2010. Causal attributions of success and failure made by undergraduate students in an introductory-level computer programming course. Computers \& Education, 54: 1127-1136.

Kay, R.H. and LeSage, A., 2009. A strategic assessment of audience response systems used in higher education. Australasian Journal of Educational Technology, 25(2): 235249.

Kehrwald, B., 2008. Towards community-based learner support: a case study. In: R. Atkinson and C. McBeath (Editors), ASCILITE 2008 Melbourne: hello! where are you in the landscape of educational technology?, Melbourne, Vic, Australia, pp. 479-483.

Kek, M.Y.C.A. and Huijser, H., 2011. The power of problembased learning in developing critical thinking skills: preparing students for tomorrow's digital futures in today's classrooms. Higher Education Research and Development, 30(3): 329-341.

Kordaki, M., 2010. A drawing and multi-representational computer environment for beginners' learning of programming using C: Design and pilot formative evaluation. Computers \& Education, 54: 69-87.
Preston, G. et al., 2010. Web-based lecture technologies : highlighting the changing nature of teaching and learning. Australasian Journal of Educational Technology, 26(6): 717728.

Veenendaal, B., 2001. Flexible assessment in GIScience education. In: A. Herrmann and M.M. Kulski (Editors), 10th Annual Teaching Learning Forum, Perth, Western Australia.

von Konsky, B.R., Ivins, J. and Gribble, S.J., 2009. Lecture attendance and web based lecture technologies : a comparison of student perceptions and usage patterns. Australasian Journal of Educational Technology, 25(4): 581-595.

\section{ACKNOWLEDGEMENTS}

The authors would like to thank the tutors and students of Spatial Computations 181 and 581 who provided their feedback and suggestions towards the continuing process of enhancing this unit. Also, the support and funding for this project contributed by the Department of Spatial Sciences and the Faculty of Science and Engineering at Curtin University is gratefully acknowledged. 